\title{
Fatigue Performance of an Injection-Molded Short E-Glass Fiber-Reinforced Polyamide 6,6. I. Effects of Orientation, Holes, and Weld Line
}

\author{
Yuanxin Zhou, P.K. Mallick \\ Center for Lightweighting Automotive Materials and Processing, University of Michigan-Dearborn, \\ Dearborn, Michigan 48128
}

\begin{abstract}
This article presents the experimental results of stresscontrolled fatigue tests of an injection-molded $33 \mathrm{wt} \%$ short E-glass fiber-reinforced polyamide 6,6 . The effects of specimen orientation with respect to the flow direction, hole stress concentration, and weld line on the fatigue life have been considered. In addition, the effect of cyclic frequency has been examined. In addition to the modulus and tensile strength, the fatigue strength of the material was significantly higher in the flow direction than normal to the flow direction, indicating inherent anisotropy of the material caused by flow-induced orientation of fibers. The presence of weld line reduced the modulus, tensile strength, failure strain, and fatigue strength. The fatigue strength of specimens with a hole was lower than that of un-notched specimens, but was insensitive to the hole diameter. At cyclic frequencies $\leq 2 \mathrm{~Hz}$, failure was due to fatigue, and fatigue life increased with frequency. However, at cyclic frequencies $>2 \mathrm{~Hz}$, the failure mode was a mixture of fatigue and thermal failures, and fatigue life decreased with increasing frequency. POLYM. COMPOS., 27:230-237, 2006. () 2006 Society of Plastics Engineers
\end{abstract}

\section{INTRODUCTION}

During the past several years, short glass fiber-reinforced polyamide 6,6 (GF/PA 6,6) has found an increasing number of applications in the automotive industry, such as engine air intake manifold, steering column bracket, and cooling fan housing [1]. It is also used in many other applications, such as bicycle wheels, fan blades, hand tools, and machine parts. Many of these parts or components experience cyclic loads, sometimes in the form of low-amplitude vibrations over extended periods of time, and are therefore prone to fatigue failure in service. Since this raises concern about their operations and long-term durability, greater attention needs to be paid to their design against fatigue failure.

Correspondence to: P.K. Mallick; e-mail: pkm@umich.edu Contract grant sponsor: TRW Education Foundation. DOI 10.1002/pc.20182

Published online in Wiley InterScience (www.interscience.wiley. com).

C 2006 Society of Plastics Engineers
Mechanical behavior of GF/PA 6,6 composites has been the subject of many studies over the last few years. For example, Leach and Moore [2] and Akay et al. [3] studied the fracture toughness and impact behavior of GF/PA 6,6. Thomason [4] studied the influence of fiber strength and fiber diameter on the tensile, flexural, and impact properties of GF/PA 6,6. Levay et al. [5] investigated the effect of testing condition on their static tensile properties and fracture strength. Jia and Kagan [6] conducted tension-tension fatigue tests on GF/PA 6,6 at various test temperatures ranging from $-40^{\circ} \mathrm{C}$ to $121^{\circ} \mathrm{C}$ and observed that the fatigue strength decreased with increasing test temperature. Handa et al. [7] reported the effect of cyclic frequency on the temperature rise in stress-controlled fatigue of GF/PA 6,6. In a recent paper, Noda et al. [8] examined the fatigue failure mechanisms in GF/PA 6,6. There are also a few publications [9-11] on the fatigue crack propagation in GF/PA 6,6 in which the fracture mechanics approach has been used to relate the fatigue crack propagation rate to stress intensity factor.

This article presents the results of a study on the effect of several test conditions on the stress-controlled fatigue behavior of an injection-molded short E-glass fiber-reinforced polyamide 6,6. More specifically, the effects of the specimen orientation relative to the flow direction in the mold, presence of weld line, presence of hole stress concentration, and cyclic frequency on the fatigue properties of this material have been investigated. In a previous study [12], we have reported the effect of mean stress on the fatigue strength of the same material. The intent of this article is to generate information on the fatigue properties that can be used in the design of cyclically stressed parts of GF/PA 6,6.

Flow-induced fiber orientation and weld lines are common features of the injection molding process. Flow-induced fiber orientation manifests in higher tensile properties in the direction of flow compared to normal to the direction of flow [13-15]. Weld lines are formed when two or more flow fronts join, as the liquid polymer fills the injection mold cavity. In general, the tensile strength of the material in the welded zone is lower than the nominal tensile strength 
of the material. Although several studies have been conducted to understand the mechanism of weld line formation and the static strength of weld lines [16-18], there are not many reported studies on the fatigue performance of weld lines. One of these studies was by Boukhili et al. [19], in which static and fatigue characteristics of injection-molded glass fiber-reinforced polycarbonate were considered. In this study, a large reduction in fatigue life was observed over the whole range of fatigue stress amplitudes considered.

The effect of stress concentration on the fatigue life of polymers has been studied only to a limited extent. As expected, the general effect of the presence of stress concentration is to reduce the fatigue life. For example, Wolf and Diboll [20] observed that the fatigue strength of polyoxymethylene was a direct function of the theoretical stress concentration factor. Crawford and Benham [21] also observed a large reduction in fatigue performance of polyoxymethylene, polypropylene, and polycarbonate when a notch was introduced in these materials.

In general, cyclic frequency determines the failure mode of polymers during fatigue tests, which can be either a thermal failure or a fatigue failure [22, 23]. However, the sensitivity to frequency depends on the polymer type. For example, polymethyl methacrylate and polyoxymethylene show strong sensitivity to frequency, while polyamide 6,6 and polycarbonate show little or no sensitivity to frequency. Frequency also determines the stress level at which thermal failure occurs before fatigue failure. For example, in polyoxymethylene, thermal failure occurred at stress levels higher than 21.6 MPa, if the frequency was $5 \mathrm{~Hz}$; however, if the frequency was reduced to $1.7 \mathrm{~Hz}$, the threshold stress for thermal failure was 27.8 MPa [23].

\section{EXPERIMENTS}

The material investigated in this study was an injectionmolded short E-glass fiber-reinforced polyamide 6,6 (GF/PA 6,6). This material is commercially available under the trade name Zytel-70G33HS1L. The glass fiber content was $33 \%$ by weight, which was equivalent to $18 \%$ by volume. The number average fiber length of such a material was reported to be in the range of $0.4 \mathrm{~mm}$ [4]. The melting point of the polyamide 6,6 resin is $220^{\circ} \mathrm{C}$. Square plates $(150 \mathrm{~mm} \times 150 \mathrm{~mm})$ were injection molded from dried pellets of GF/PA 6,6 in a single edge-gated mold. The mold cavity had a $25-\mathrm{mm}$ diameter core at the center (Fig. 1). The plate thickness was $2.5 \mathrm{~mm}$. A 90-ton Toyo injection molding machine was used to mold these plates. The processing conditions were the same for all the specimens used in tensile and fatigue tests in this study.

Dog-bone shaped specimens were prepared from the injection-molded plates in three different directions-parallel to the flow direction (L-direction specimens), normal to the flow direction (W-direction specimens) and with the weld line (WL specimens). The specimen dimensions were $100 \mathrm{~mm}$ in overall length, $25 \mathrm{~mm}$ in gage length, and 12.7

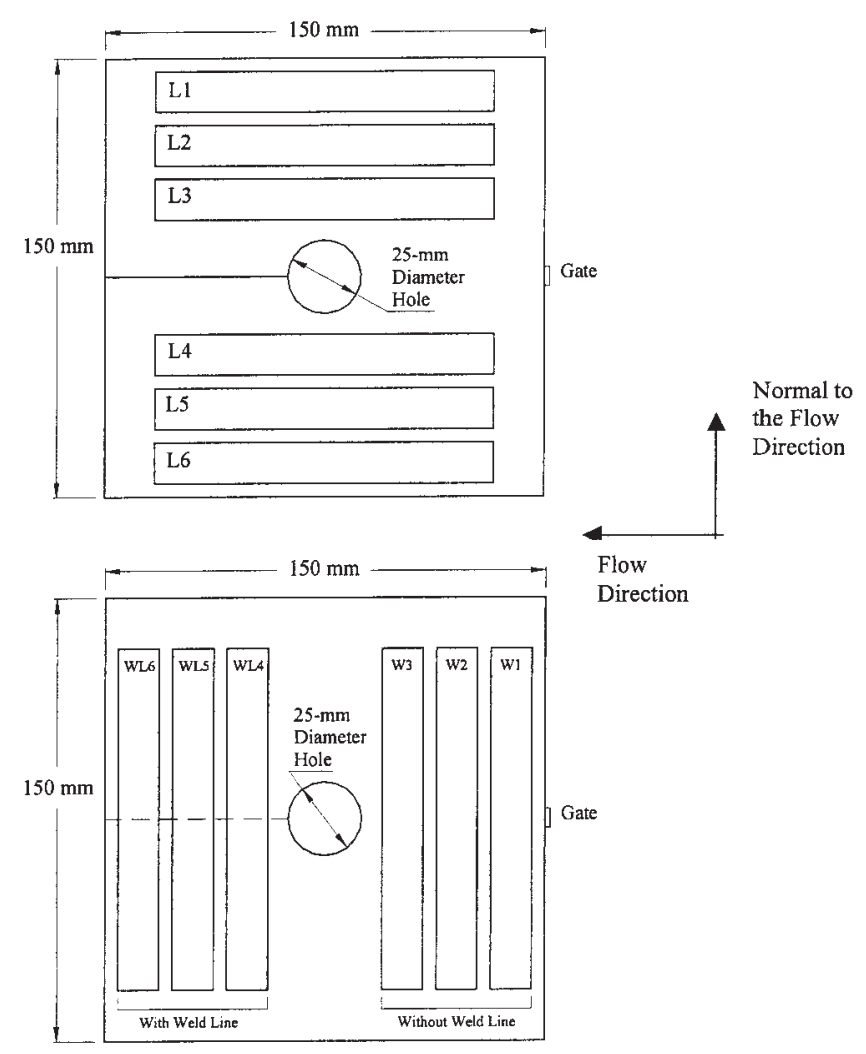

FIG. 1. The injection-molded plate dimensions and specimen locations (L: Flow direction specimens, W: Normal to the flow direction specimens, and WL: Weld line specimens).

$\mathrm{mm}$ in gage width. For the WL specimens, the weld line was located at the mid-length. The weld line was formed in the plates as the flow front was divided by the central core in the mold and then joined behind the core. This type of weld line is often referred to as Type II weld line or meld line.

Uniaxial tension tests and cyclic fatigue tests were performed on an MTS servohydraulic test machine equipped with a forced air convection oven. A strain gage extensometer ( $25 \mathrm{~mm}$ gage length) was used to measure axial strain. The tension tests were conducted at $0.05,0.5$, and $5 \mathrm{~min}^{-1}$ strain rates and at $23,50,75$, and $100^{\circ} \mathrm{C}$ test temperatures. The specimens were not dried before testing and therefore may contain certain amount of humidity. Three parameters were determined from each stress-strain curve: elastic modulus $(E)$ from the initial slope of the stress-strain curve, tensile strength $\left(\sigma_{\mathrm{b}}\right)$ corresponding to the maximum stress and failure strain $\left(\epsilon_{\mathrm{b}}\right)$. Stress-controlled cyclic fatigue tests were performed in tension-tension mode at an ambient temperature of $\sim 23^{\circ} \mathrm{C}$. The ratio of the minimum cyclic stress to the maximum cyclic stress (i.e., $R$-ratio) was 0.1 . The maximum cyclic stress ranged from $70 \%$ to $90 \%$ of the tensile strength of the material determined at $5 \mathrm{~min}^{-1}$ and $23^{\circ} \mathrm{C}$. Except for the frequency effect study, all fatigue tests were conducted at $1 \mathrm{~Hz}$ cyclic frequency. Such a low frequency was selected so that failure would occur due to fatigue instead of thermal failure.

The stress concentration effect was studied using a 


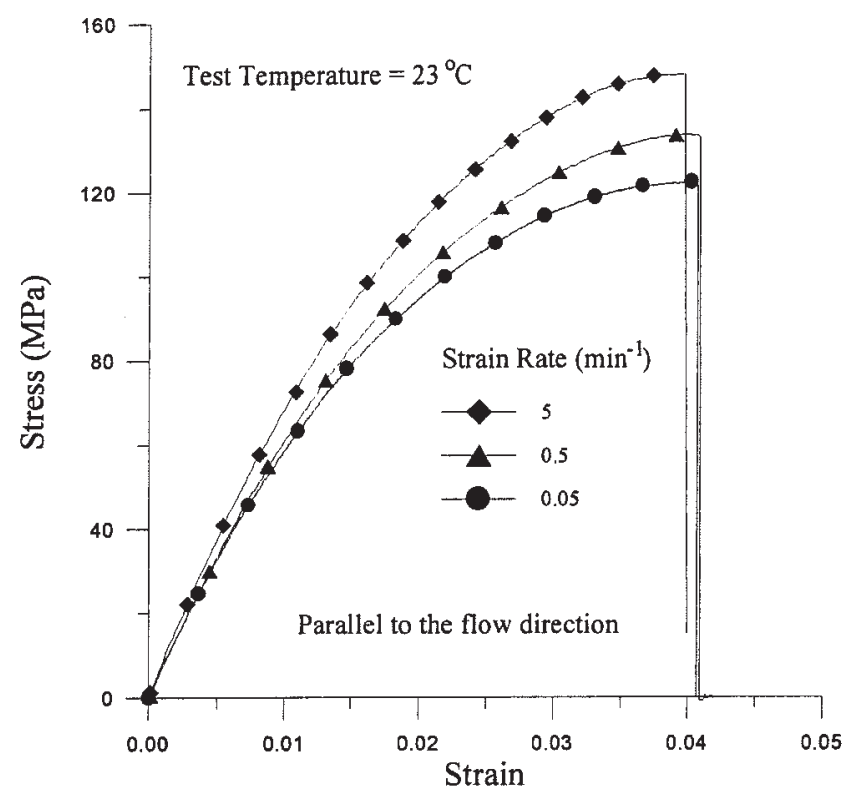

FIG. 2. Effect of strain rate on the tensile stress-strain curves of GF/PA 6,6 .

drilled circular hole at the center of the L-direction specimens only. The hole diameters were $1.58,3.17$, and 6.35 $\mathrm{mm}$. The theoretical stress concentration factors corresponding to these hole diameters are 2.64, 2.43, and 2.18 $\mathrm{mm}$, respectively [24]. The frequency effect was studied, also with the L-direction specimens, using $0.5,1,2,5,10$, and $20 \mathrm{~Hz}$. The maximum cyclic stress level was 55\% and $70 \%$ of the tensile strength of the material.

\section{RESULTS}

\section{Tensile Properties}

The tensile stress-strain curves of GF/PA 6,6 at different strain rates and test temperatures are shown in Figs. 2 and 3, respectively. These specimens were in the flow or L-direction of the injection molded plates. All specimens failed immediately after reaching the maximum stress; however, the stress-strain curves showed considerable nonlinearity even at $23^{\circ} \mathrm{C}$. As shown in Table 1 , both modulus and tensile strength increased with increasing strain rate, but decreased with increasing test temperature; however, failure strain was not affected significantly by either temperature or strain rate.

Figure 4 shows the tensile stress-strain curves of GF/PA 6,6 for L-direction, $\mathrm{W}$-direction, and $\mathrm{WL}$ specimens. The test temperature and strain rate were $23^{\circ} \mathrm{C}$ and $5 \mathrm{~min}^{-1}$, respectively. Both modulus and tensile strength of the Ldirection specimens were much higher than those of the $\mathrm{W}$-direction specimens, but the failure strain in the Ldirection was lower. The presence of weld line reduced the modulus, tensile strength, and failure strain even further. The difference in tensile properties in the flow (L) and

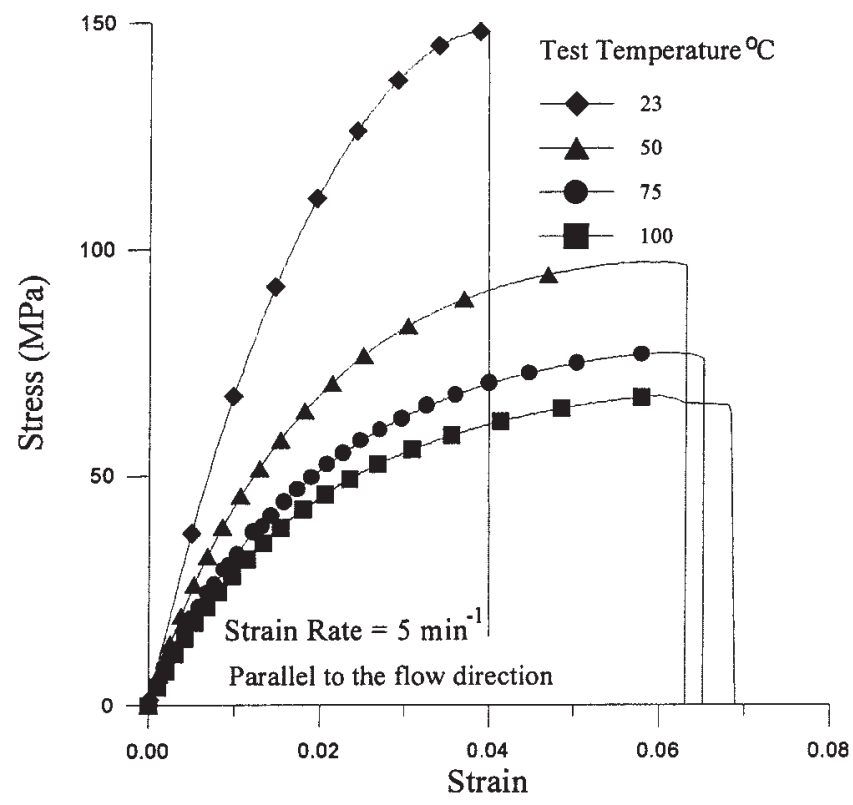

FIG. 3. Effect of test temperature on the tensile stress-strain curves of GF/PA 6,6.

normal to the flow (W) direction is an indication of inherent anisotropy in the injection-molded plates, which can be attributed to the preferred orientation of short E-glass fibers in the flow direction. This will be discussed later.

\section{Fatigue Properties}

Effect of Frequency. The frequency effect on the fatigue life of GF/PA 6,6 is shown in Fig. 5. Maximum cyclic stress levels for these specimens were $55 \%$ and $70 \%$ of the tensile strength. At both maximum cyclic stress levels, fatigue life increased with increasing frequency at frequencies less than $2 \mathrm{~Hz}$. At frequencies greater than $2 \mathrm{~Hz}$, fatigue life decreased with increasing frequency. At $0.5,1$, and $2 \mathrm{~Hz}$, the specimens failed by fatigue. The failure mode at 5,10 , and $20 \mathrm{~Hz}$ was a combination of fatigue failure and thermal failure. From the hysteresis loops recorded during the fatigue tests, it was observed that at lower frequencies, the slopes of the hysteresis loops remained approximately the same during fatigue cycling and the strain amplitude did not increase appreciably, but the mean strain increased with

TABLE 1. Tensile properties of GF/PA 6,6 at different temperatures and strain rates (L-direction specimens).

\begin{tabular}{lccrc}
\hline $\begin{array}{l}\text { Test } \\
\text { temperature } \\
\left({ }^{\circ} \mathrm{C}\right)\end{array}$ & $\begin{array}{c}\text { Strain } \\
\text { rate } \\
\left(\mathrm{min}^{-1}\right)\end{array}$ & $\begin{array}{c}\text { Tensile } \\
\text { modulus } \\
(\mathrm{GPa})\end{array}$ & $\begin{array}{c}\text { Tensile } \\
\text { strength } \\
(\mathrm{MPa})\end{array}$ & $\begin{array}{c}\text { Failure } \\
\text { strain } \\
(\%)\end{array}$ \\
\hline & 0.05 & 7.26 & 122.6 & 3.98 \\
23 & 0.5 & 7.36 & 133.8 & 3.93 \\
23 & 5 & 8.30 & 148.1 & 3.93 \\
23 & 5 & 4.42 & 95.3 & 6.13 \\
50 & 5 & 3.51 & 76.8 & 6.50 \\
75 & 5 & 2.17 & 70.8 & 6.83 \\
100 & & & & \\
\hline
\end{tabular}




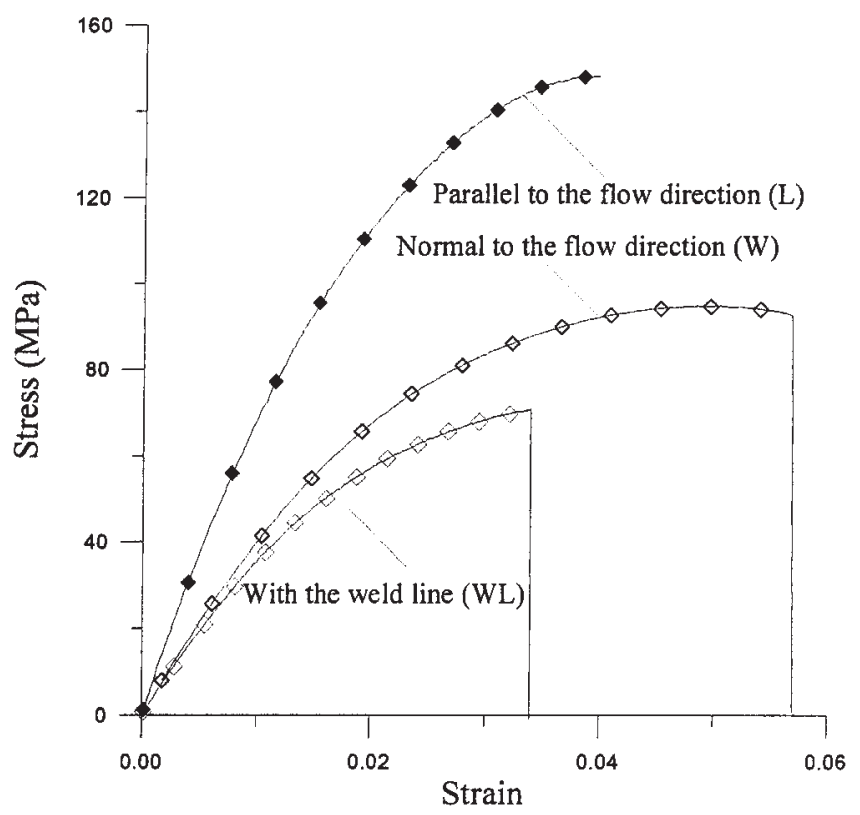

FIG. 4. Tensile stress-strain curves of GF/PA 6,6 parallel to the flow direction (L), normal to the flow direction (W), and with weld line (WL).

increasing number of cycles. At higher frequencies, there was not only an increase in mean strain but also a decrease in the slopes of the hysteresis loops. The increase in mean strain can be attributed to creep, which occurred at both low and high frequencies. The decrease in the slopes of the hysteresis loops may be due to increase in temperature of the specimen due to hysteretic heating.

Handa et al. [7] also reported that the fatigue life of a similar GF/PA 6,6 was significantly lower at $20 \mathrm{~Hz}$ compared to that at $5 \mathrm{~Hz}$. They also noted a sharp temperature increase at both the initial and the final stages of fatigue life. The temperature increase occurs due to a combination of internal heat generation by viscoelastic energy dissipation in each fatigue cycle and low thermal conductivity of the material. The amount and rate of heat generation depend on cyclic frequency, the maximum stress applied during cycling, the loss modulus as well as the storage modulus of the polymer. Internal heat generation and consequent temperature rise may cause failure by thermal softening instead of fatigue.

Effect of Specimen Orientation and Weld Line. Figure 6 shows the fatigue S-N curves of the GF/PA 6,6 in the flow (L) direction and normal to the flow (W) direction. In this figure, the vertical axis represents the maximum cyclic stress and the horizontal axis is the number of fatigue cycles to failure. As can be observed from Fig. 6, the fatigue strength of GF/PA 6,6 in the L-direction was significantly higher than that in the W-direction. Figure 6 also shows the $\mathrm{S}-\mathrm{N}$ curve for the WL specimens containing the weld line. These specimens showed the lowest fatigue strength. The fatigue strength of the WL specimens was closer to the fatigue strength of the Wdirection specimens; however, it was nearly $55 \%$ lower than that of the L-direction specimens.
In fatigue studies with metals [25], it is common to describe the $\mathrm{S}-\mathrm{N}$ curves by power law equation of the following type:

$$
\sigma=\sigma_{\mathrm{f}}\left(N_{f}\right)^{b}
$$

where, $\sigma$ is maximum cyclic stress, $N_{\mathrm{f}}$ is number of cycles to failure, $\sigma_{\mathrm{f}}$ is fatigue strength coefficient, and $b$ is fatigue strength exponent.

Similar approach was used here to describe the S-N curves of GF/PA 6,6. The following equations were obtained by using the curve fitting technique.

$$
\begin{gathered}
\sigma=156\left(N_{\mathrm{f}}\right)^{-0.057} \text { (In the flow direction) } \\
\sigma=102\left(N_{\mathrm{f}}\right)^{-0.060} \text { (Normal to the flow direction) } \\
\sigma=82.5\left(N_{\mathrm{f}}\right)^{-0.067} \text { (Weld line specimens) }
\end{gathered}
$$

On the basis of the fatigue strength data of the Wdirection and WL specimens relative to the L-direction specimens, a flow orientation factor $\left(K_{\mathrm{O}}\right)$ and a weld line factor $\left(K_{\mathrm{WL}}\right)$ are defined as follows:

$$
K_{\mathrm{O}}=\frac{\text { Fatigue Strength Normal to the Flow Direction }}{\text { Fatigue Strength in the Flow Direction }}
$$

and

$$
K_{\mathrm{WL}}=\frac{\text { Fatigue Strength of the Weld Line }}{\text { Fatigue Strength in the Flow Direction }} .
$$

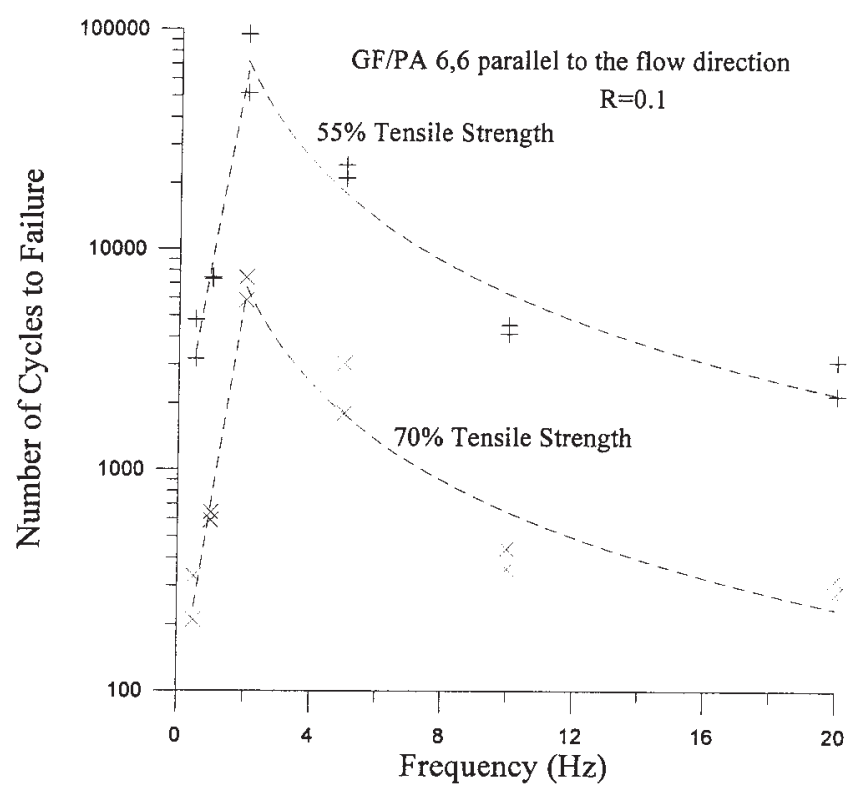

FIG. 5. Effect of cyclic frequency on the fatigue life of GF/PA 6,6 ( $R$ $=0.1$ ). 
TABLE 2. Fatigue parameters of GF/PA 6,6 with and without hole.

\begin{tabular}{|c|c|c|c|c|c|}
\hline \multirow[b]{2}{*}{ Specimen type } & \multirow[b]{2}{*}{ Condition } & \multicolumn{2}{|c|}{ Based on gross stress } & \multicolumn{2}{|c|}{ Based on net stress } \\
\hline & & $\sigma_{\mathrm{f}}(\mathrm{MPa})$ & $b$ & $\sigma_{\mathrm{f}}(\mathrm{MPa})$ & $b$ \\
\hline L-direction & Without hole & 156 & -0.057 & - & - \\
\hline L-direction & With a $1.58-\mathrm{mm}$ diameter hole & 124 & -0.085 & 157 & -0.085 \\
\hline L-direction & With a $3.17-\mathrm{mm}$ diameter hole & 118 & -0.103 & 156 & -0.083 \\
\hline L-direction & With a $6.35-\mathrm{mm}$ diameter hole & 103 & -0.120 & 156 & -0.083 \\
\hline W-direction & Without hole & 102 & -0.060 & - & - \\
\hline With weld line (WL) & Without hole & 82.5 & -0.067 & - & - \\
\hline
\end{tabular}

The flow orientation factor $K_{\mathrm{O}}$ and the weld line factor $K_{\mathrm{WL}}$ are plotted in Fig. 7 as a function of the number of cycles to failure. Both factors decreased with increasing number of cycles, indicating that the sensitivity to these factors decreases at long lives. Furthermore, the weld line factor was smaller than the orientation factor, indicating that weld line caused a greater reduction in fatigue strength than the flow-induced fiber orientation; however, as Fig. 7 indicates, it was not as sensitive to the number of cycles as the orientation factor.

Effect of Stress Concentration. The fatigue S-N curves of the L-direction specimens with different central hole diameters are plotted in Figs. 8 and 9. The fatigue parameters, $\sigma_{\mathrm{f}}$ and $\mathrm{b}$, of the material, with and without hole, are listed in Table 2. In Fig. 8, the vertical axis represents the remote stress, i.e., the stress based on gross cross-sectional area. Based on remote stress, it appears that the fatigue strength decreased with increasing hole diameter. The same fatigue data were plotted in Fig. 9, in which the vertical axis represents the net stress calculated by dividing the maximum cyclic load by the net area across the hole. Even

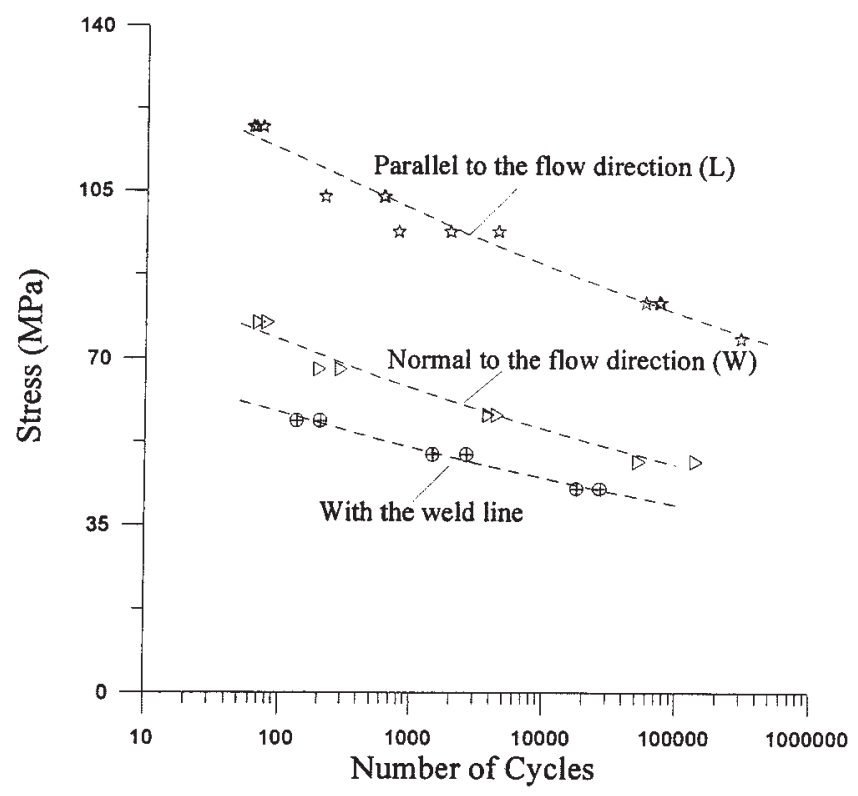

FIG. 6. Effect of specimen orientation on the S-N curves of GF/PA 6,6. though the theoretical stress concentration factors for the three hole diameters were quite different, the net area-based fatigue strengths of specimens with all three hole diameters fell on the same S-N curve; however, this curve was lower than the $\mathrm{S}-\mathrm{N}$ curve for the specimens without any hole. This indicates that the fatigue strength of short E-glass-reinforced polyamide 6,6 was sensitive to the presence of holes, but not to the relative hole diameter.

In fatigue studies on metals [23], the fatigue stress concentration factor $K_{\mathrm{f}}$ is defined as:

Fatigue strength without a

$$
K_{\mathrm{f}}=\frac{\text { geometric discontinuity at } N \text { cycle }}{\text { Fatigue strength with a }} \text {. }
$$

By comparing the $\mathrm{S}-\mathrm{N}$ curves in Fig. 9, the fatigue stress concentration factor $K_{\mathrm{f}}$ can be written as:

$$
K_{\mathrm{f}}=1.0161\left(N_{\mathrm{f}}\right)^{0.03375}
$$

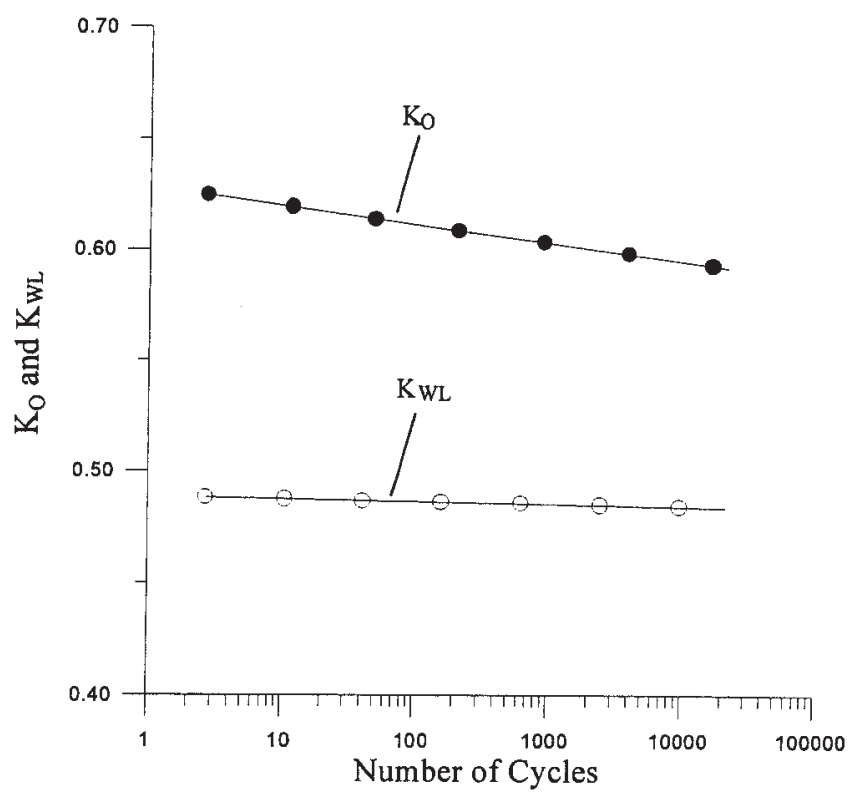

FIG. 7. Orientation factor $\left(K_{\mathrm{O}}\right)$ and weld line factor $\left(K_{\mathrm{WL}}\right)$. 


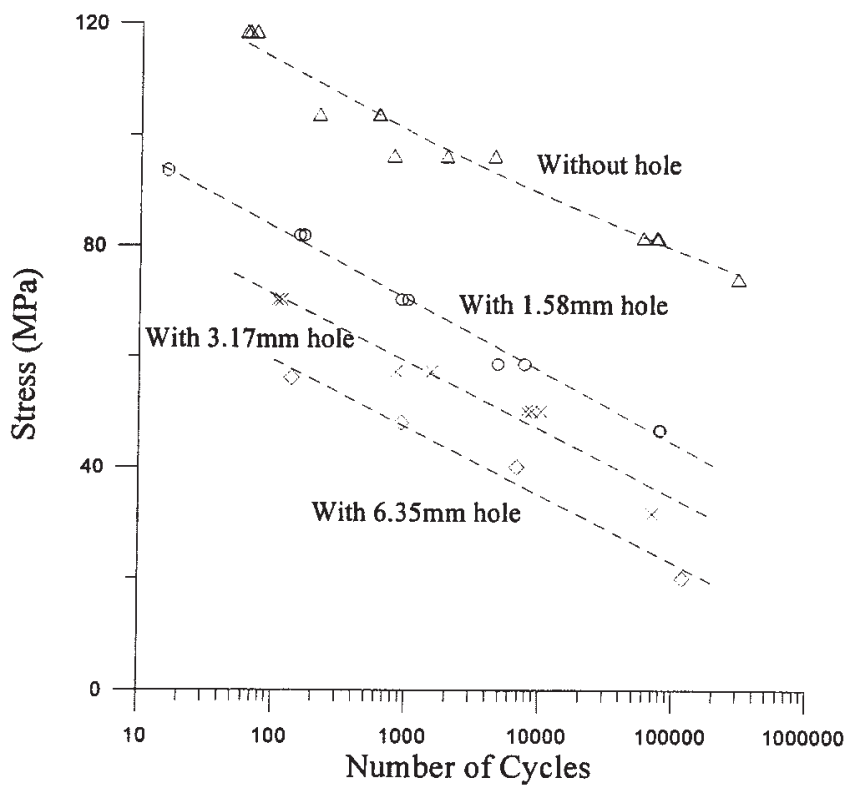

FIG. 8. Effect of hole diameter on the S-N curves of GF/PA 6,6.

The fatigue stress concentration factor $K_{\mathrm{f}}$ increased with cycle number.

\section{Microstructural Examinations}

The significant difference in tensile and fatigue properties of specimens in the L- and W-directions indicates the presence of inherent anisotropy in the injection-molded plates, which may have been caused by the preferential orientation of fibers. The higher modulus, higher tensile strength, and lower failure strain in the flow direction are

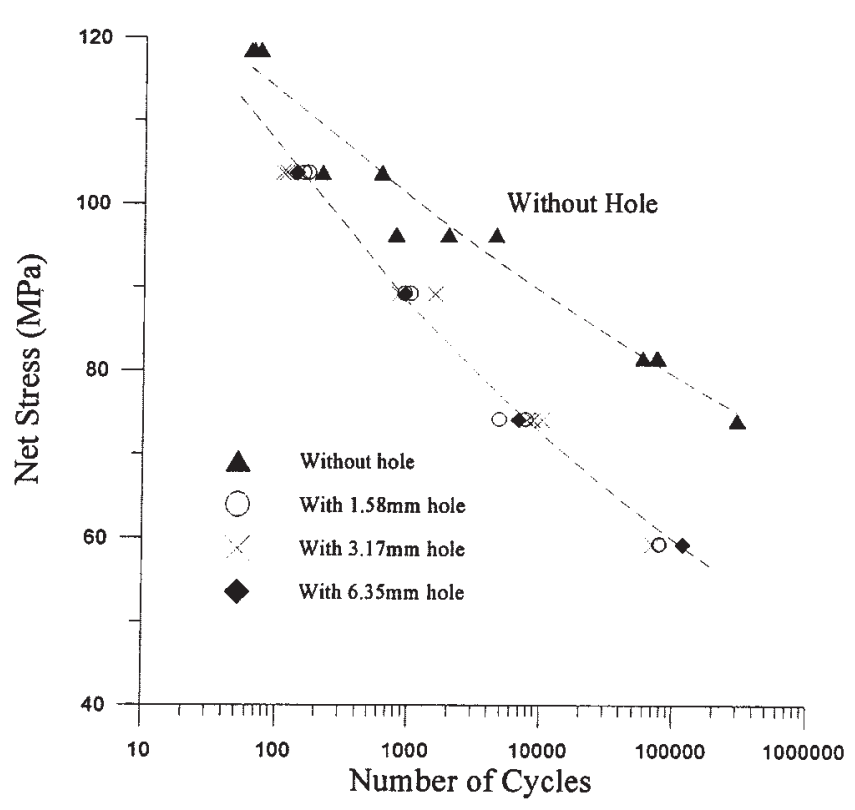

FIG. 9. Effect of hole diameter on the net stress-based S-N curves of GF/PA $6,6$.

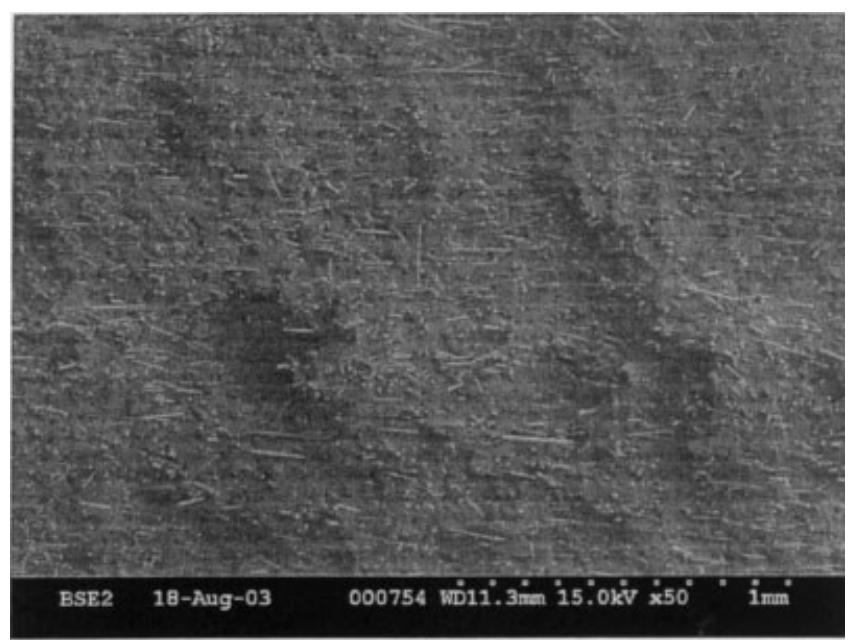

(A)

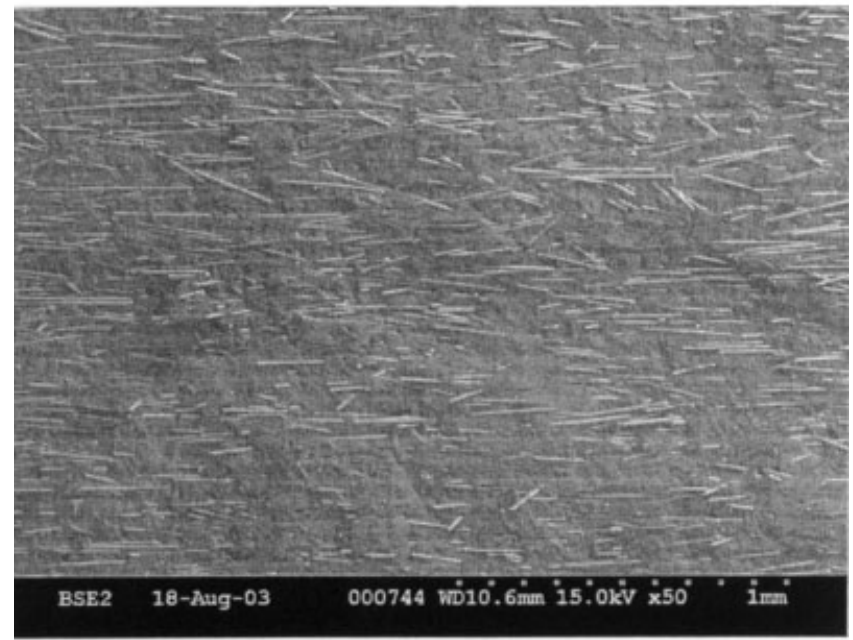

(B)

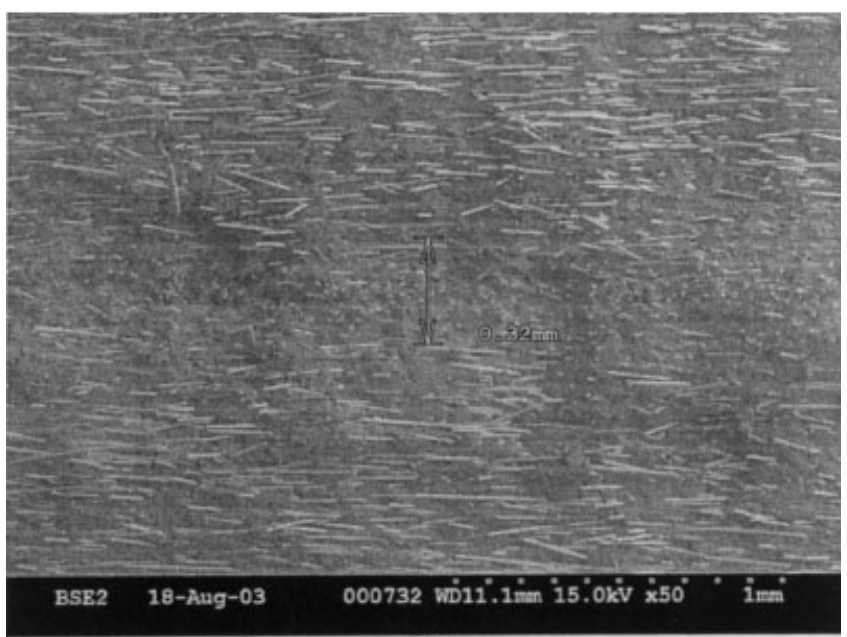

(C)

FIG. 10. Fracture surfaces of GF/PA 6,6 fatigue specimens (at 40×). A: parallel to the flow direction; $\mathrm{B}$ : with weld line; $\mathrm{C}$ : normal to the flow direction. 


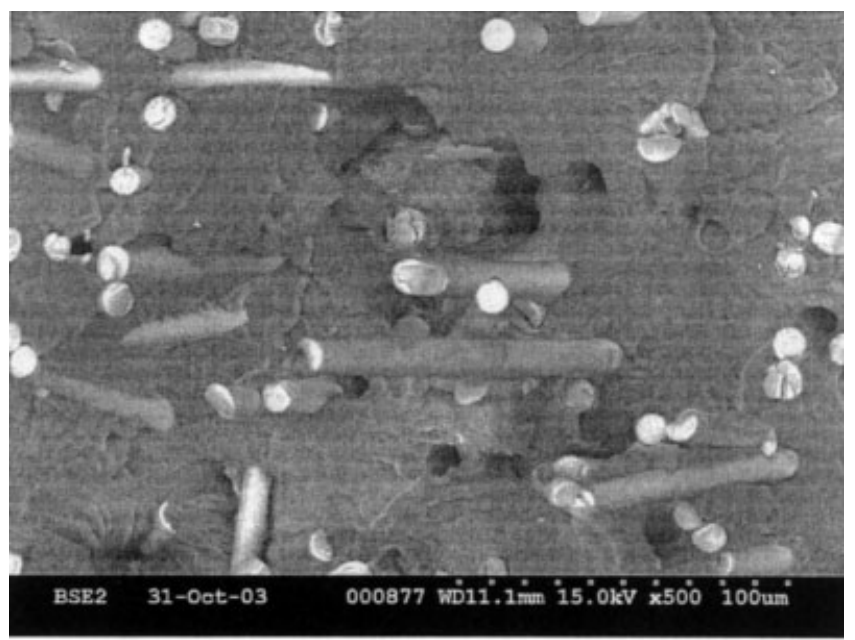

(A)

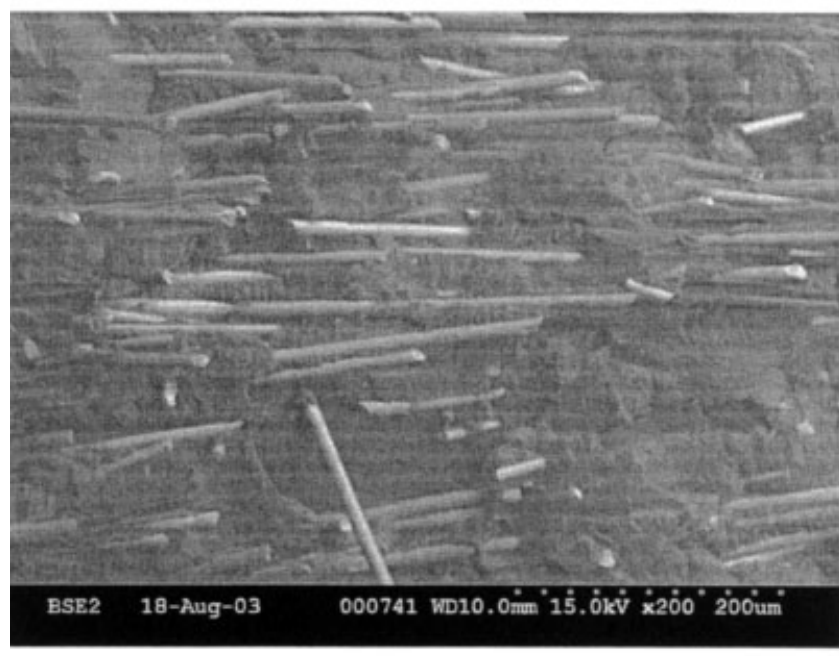

(B)

FIG. 11. Fracture surfaces of GF/PA 6,6 fatigue specimens (at 200×). A: Fiber orientation is parallel to the loading direction. B: Fiber orientation is normal to the loading direction.

indications that the short fibers in the plates were preferentially oriented in that direction.

Figure 10A-10C shows the SEM photographs of fracture surfaces of GF/PA 6,6 fatigue specimens in the flow direction, with the weld line, and normal to the flow direction, respectively. For the specimen in the flow direction, the majority of the glass fibers were oriented normal to the fracture surface or parallel to the principal flow direction. Since this is also the loading direction, the L-direction specimens exhibited the highest modulus and strength properties. For the specimen with the weld line, the majority of the glass fibers were oriented parallel to the fracture surface or normal to the loading direction. For the specimen normal to the flow direction, a skin-core morphology was clearly visible. The core, located at the mid-thickness region of the specimen, was a narrow band of fibers oriented normal to the fracture surface or parallel to the loading direction. The fiber orientation in the skins, on the other hand, was parallel to the fracture surface or normal to the loading direction. Since the modulus and strength of the material are highly dependent on fiber orientation relative to the loading direction, the greater the fiber orientation parallel to the loading direction, the higher is the modulus and strength of the material. This explains the highest strength and modulus for the L-direction specimens, the lowest strength and modulus for the WL specimens, and intermediate strength and modulus for the W-direction specimens.

Figure 11 shows higher magnification SEM photographs of the fracture surfaces from the L-direction and W-direction specimens. A very thin coating of the matrix can be observed on the surfaces of the pulled-out fibers in Fig. 11A, indicating that there was a relatively good interfacial bond between the fibers and the polyamide 6,6 matrix. The relatively flat fracture surface of the matrix surrounding the fibers does not indicate extensive plastic deformation. Figure 11B shows the section of the Wdirection specimen where the fibers were mostly normal to the loading direction. In this case, the appearance of the fiber surfaces indicates that the fatigue crack progressed along the fiber-matrix interface as well as in the matrix surrounding the fibers.

\section{CONCLUSIONS}

Static tensile tests, fatigue tests, and microstructural observations show that injection-molded short E-glass fiber-reinforced polyamide 6,6 had significant anisotropy due to preferred orientation of fibers in the flow direction. The modulus, tensile strength, and fatigue strength of composite were all higher in the flow direction than those normal to the flow direction. The presence of weld line caused a significant reduction in modulus, tensile strength, elongation, and fatigue strength of the material. The fatigue strength of the material was also reduced by the presence of hole stress concentration.

Both fatigue life and fatigue failure were affected by cyclic frequency. At frequencies $\leq 2 \mathrm{~Hz}$, the failure mode of GF/PA 6,6 was due to fatigue and the fatigue life increased with frequency. However, at frequencies $\geq 2$ $\mathrm{Hz}$, a combination of fatigue and thermal failures took place and the fatigue life decreased with increasing the frequency.

\section{REFERENCES}

1. J.L. Broge, Auto. Eng., 108, 70 (2000).

2. D.C. Leach, and D.R. Moore, Composites, 16, 113 (1985).

3. M. Akay, D.F. O'Regan, and R.S. Bailey, Compos. Sci. Technol., 55, 109 (1995).

4. J.L. Thomason, Compos. Sci. Technol., 59, 2315 (1999).

5. I. Lévay, G.B. Lenkey, L. Tóth, and Z. Major, J. Mater. Proc. Tech., 133, 143 (2003). 
6. N. Jia and V.A. Kagan, Polym. Compos., 19, 408 (1998).

7. K. Handa, A. Kato, and I. Narisawa, J. Appl. Polym. Sci., 72, 1783 (1999).

8. K. Noda, A. Takahara, and T. Kajiyama, Polymer, 42, 5903 (2001).

9. R.W. Lang, J.A. Manson, and R.W. Hertzberg, "Fatigue Crack Propagation in Short Glass Fiber Reinforced Nylon 66: Effect of Frequency," in Role of the Polymeric Matrix in the Processing and Structural Properties of Composite Materials, J.C. Seferis and L. Nicolais, eds., Plenum, New York (1983).

10. J. Karger-Kocsis and K. Friedrich, Composites, 19, 105 (1988).

11. M.G. Wyzgoski and G.E. Novak, J. Mater. Sci., 26, 6314 (1991).

12. P.K. Mallick and Y. Zhou, Int. J. Fatig., 26, 941 (2004).

13. M.W. Darlington, P.L. McGinley, and G.R. Smith, J. Mater. Sci., 11, 877 (1976).

14. M. Akay and D. Barkley, J. Mater. Sci., 26, 2731 (1991).

15. S.E. Barbosa and J.M Kenny, J. Reinforc. Plast. Compos., 18, 413 (1999).
16. T. Tjäder, J. Seppälä, and P. Jääskeläinen, J. Mater. Sci., 33, 923 (1998).

17. D. Jarus, J.W. Summers, A. Hiltner, and E. Baer, Polymer, 41, 3057 (2000).

18. R. Seldén, Polym. Eng. Sci., 37, 205 (1997).

19. R. Boukhili, R. Gauvin, and M. Gosselin, "Fatigue Characteristics of Weld-Lines in Injection Molded Glass Fiber Reinforced Polycarbonate," in Development and Design with Advanced Materials, G.C. Sih, S.V. Hoa, and J.T. Pindera, eds., Elsevier Science, New York (1990).

20. L.J. Wolf and W.B. Diboll Jr., J. Eng. Ind. Trans. ASME, Aug, 319 (1965).

21. R.J. Crawford and P.P. Benham, Polymer, 16, 908 (1975).

22. R.W. Hertzberg and J.A. Manson, Fatigue of Engineering Plastics, Academic Press, San Diego, CA (1980).

23. J.A. Sauer and G.C. Richardson, Int. J. Frac., 16, 499 (1980).

24. R.J. Roark and W.C. Young, Formulas for Stress and Strain, 5th edn., McGraw-Hill, New York (1975).

25. J.A. Bannantine, J.J. Comer, and J.L. Handrock, Fundamentals of Metal Fatigue Analysis, Prentice Hall, Englewood Cliffs, NJ (1990). 